\title{
Quantitative influence of thermal stress on fiber quality traits of cotton (Gossypium hirsutum L.)
}

Khadim Hussain $^{1}$, Azmat Hussain ${ }^{2}$, Danish Iqbal ${ }^{1 *}$, Muhammad Ilyas Sarwar ${ }^{1}$, Abdul Qayyum ${ }^{3}$, Mubashir Islam Gill ${ }^{1}$ and Niaz Ahmed Wahocho ${ }^{4}$

1. Central Cotton Research Institute, Multan-Pakistan

2. University College of Textile Engineering, Bahauddin Zakariya University, Multan-Pakistan

3. Plant Breeding \& Genetics Department, Bahauddin Zakariya University, Multan-Pakistan

4. Department of Horticulture, Sindh Agriculture University Tando Jam-Pakistan

*Corresponding author's email: danish.iqbal@ymail.com

Citation

Khadim Hussain, Azmat Hussain, Danish Iqbal, Muhammad Ilyas Sarwar, Abdul Qayyum, Mubashir Islam Gill and Niaz Ahmed Wahocho. Quantitative influence of thermal stress on fiber quality traits of cotton (Gossypium hirsutum L.). Pure and Applied Biology. Vol. 9, Issue 4, pp2461-2469. http://dx.doi.org/10.19045/bspab.2020.90261

Received: 00/04/2020 Revised: 00/06/2020 Accepted: 00/07/2020

Online First: 28/07/2020

\section{Abstract}

Temperature is the main controlling factor for plant growth, development, reproduction and fruit ripening rate. Twenty genotypes of cotton (Gossypium Hirsutum L.) were screened to determine the consequence of heat stress on fibre traits. To expose the genotypes against two different thermal conditions, two sowing dates were adopted. Significant differences were observed under both conditions among the genotypes as well. The genotypes were categorized in nine groups depending on heat susceptibility index and quality parameters. Some genotypes showed significant tolerance against heat stress with good fibre traits. Cyto-178 showed low heat susceptible index (HSI)with acceptable fibre length $(28.5 \mathrm{~mm}) \&$ uniformity index $(84.9 \%)$ in the same way DAI-16 showed low HSI with good fibre strength (101tppsi) and NIAB-111 showed maximum ginning out turn $(42.1 \%)$ with low HSI.

Keywords: Heat Stress Index; Fibreproperties; Temperature

\section{Introduction}

Cotton is the major textile fiber plant in the world, it is an important part of international agriculture and the backbone of many developing and developed economies. Cotton is a major source of employment for millions of people engaged in cultivation, textile production and trade activities, and it accounts for a significant proportion of many countries ' gross national product, including Pakistan, China, India, Australia, Greece and
Uzbekistan [1].The cotton crop is very sensitive towards any change in macro or micro climate and management. High temperature stress plays a key role in reduction of plant growth, yield and fibre quality [2].Temperature stress affects vegetative growth, root growth, seedling growth, flowering, fruit set and ultimately yield along with quality of fibre [3]. Accumulation of photosynthate products in the cell wall of cotton fibre describes its 
quality and these products are very sensitive to environment. As resultant of severevariations in temperature, usually inhabitation of cellulose synthesis occurred which effect the fibre elongation and ultimately low quality fibre is produced [4]. Genetics of plant also play a vital role for the control of traits like fibre length, fineness and strength. The genetic control of fibre maturity is proven fact but the accumulation of cellulose layers greatly affected by abiotic stresses [5]. Thus, it is the need of time to measure the magnitude ofhigh thermal effects on fibre quality under the current scenario of climate change. During the month of peak flowering(June to July) sometimes temperature exceeds $50{ }^{\circ} \mathrm{C}$ which is very lethal for flower, boll setting and plant growth and fibre development[6, 7]. Most of the cultivars grown in Pakistan are susceptible to heat which is the major reasonin the reduction of yield and deterioration of fibre quality [8, 9]. Therefore, it is the dire need to screen out the available germplasm showing maximum tolerance against heat stress to be use in breeding program to sustain the fibre quality under stress condition in the future.This research study was performed to determine the impact of heat stress on fibre quality characteristics.

\section{Materials and methods}

Twenty upland cotton (Gossypium hirsutum L.) accessions were grown-up in field conditions at Central Cotton Research Institute (CCRI) Multan Pakistan, during cropping season 2014-15. The plots were adjusted at $6.1 \times 3.1 \mathrm{~m}$ with $30 \mathrm{~cm}$ plant to plant spacing and $75 \mathrm{~cm}$ row to row spacing. Split plot design with three replications was used for field experiments. Temperature conditions were kept in main blocks while genotypes were kept in sub blocks. First sowing was done in $1^{\text {st }}$ week of April (heat stress condition) and second sowing was done in $1^{\text {st }}$ week of May (normal stress condition). These two sowing dates were chosen to expose the cultivar at two different thermal conditions especially at peak flowering stage. All agronomic activities were conducted according to standard requirement.Seed cotton produced by each plant was weighed after manually cleaning and ginned by laboratory scale saw gin machine. Total lint weight was recorded, and the following formula in equation (1) determined Ginning out turn percentage GOT $(\%)$.

Ginning out turn $(\%)=($ Weight of lint in a sample/ Weight of seed cotton) $\times 100$ For estimating fibre length, uniformity index, strength and micronaire, a sample of $40 \mathrm{~g}$ lint which was collected from each genotype in each replication. HVI (High Volume Instrument) at fibre technology section of Central Cotton Research Institute, Multan was used for fibre quality testing. The procedure of conditioning and testing was adopted as given inASTM Standards [10]. In order to calculate the heat tolerance in relations of the reduction in fibre quality traits produced by favorable or unfavorable environmental conditions heat susceptibility index (HSI) was used. HSI of genotypes for fibre length, uniformity, fibre strength and micronairewas calculated according to Fisher and Maurer [11], as shown in fig 1. The rating of HSI against Genotypes as follows; for high tolerance HSI value less than or equal to 0.50 , for middle tolerance HSI value from 0.5-1.0 middle tolerant; for heat sensitive HIS is greater than 1.0 [12].

Heat susceptibility index (HSI) $=(\mathrm{GN}-$ GS/GN)/(MN-MS/MN) (2)

WhereM=Mean, N=Normal condition, $\mathrm{G}=$ Genotype, $\mathrm{S}=$ Stress condition.

Variance analysis was carried out with the aid of computer program' Statistics' v 8.1 using the approach drawn by the researcher [13].

Meteorological data table 1. was obtained from meteorological observatory at CCRI, Multan. 
Results and discussion

A significant diversity was found among the genotypes for traits under consideration and negative role of high temperature was clear. And it is evident from meteorological data that, the crop sown in early April bears the maximum mean temperature during peak flowering season which cause deterioration of the fibre traits as compared to the May sown crop.

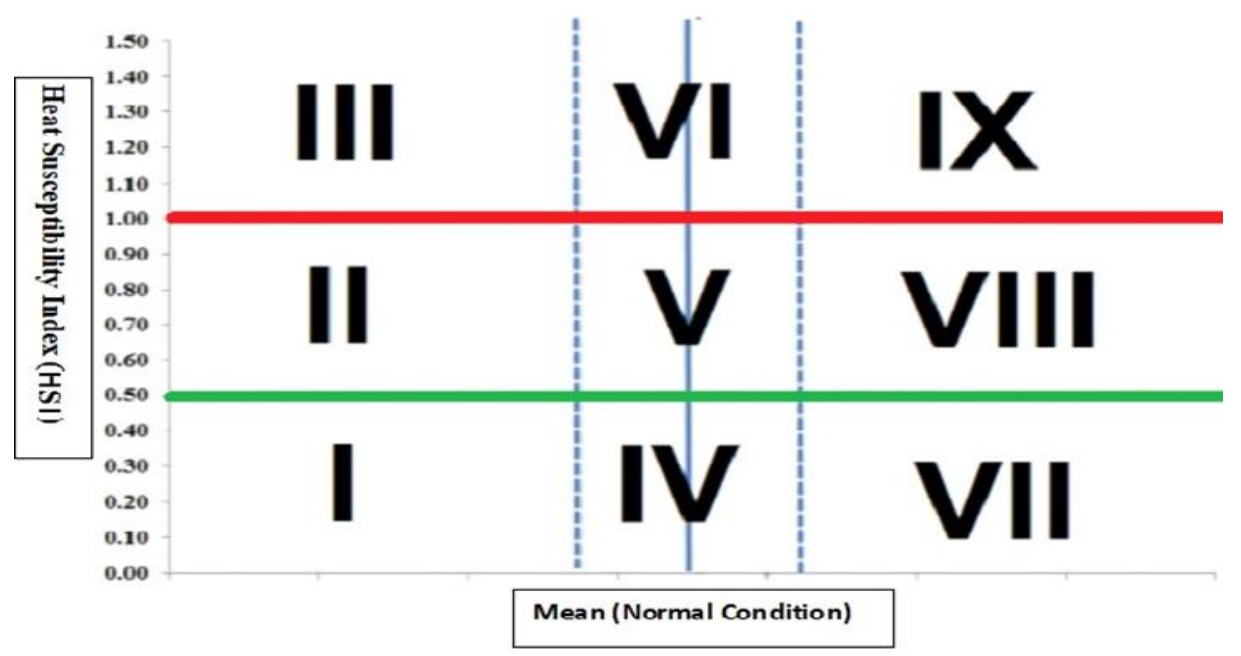

Figure 1. Region-I: $X<$ Mean \& HSI $\leq \mathbf{0 . 0 5}$, Region-II: $X<$ Mean \& $0.05<$ HSI $\leq 1.00$, Region-III: $X<$ Mean \& HSI $>1.00$, Region-IV: $X=$ Mean \& HSI $\leq 0.05$, Region-V: $X=$ Mean \& $0.05<H S I \leq 1.00$, Region-VI: $X=$ Mean \& HSI $>1.00$, Region-VII: $X>$ Mean \& HSI $\leq 0.05$, Region-VIII: $X>M e a n \&$ $0.05<$ HSI $\leq 1.00$, Region-IX: X>Mean \& HSI $>1.00$

Table 1. Meteorological Data recorded at CCRI, Multan during cropping season 2014

\begin{tabular}{|c|c|c|c|c|c|c|c|c|}
\hline \multirow[t]{2}{*}{ Month } & \multicolumn{2}{|c|}{$\begin{array}{c}\text { Air } \\
\text { Temperature } \\
\left({ }^{\circ} \mathrm{C}\right)\end{array}$} & \multicolumn{2}{|c|}{$\begin{array}{l}\text { Relative } \\
\text { Humidity }\end{array}$} & \multirow{2}{*}{$\begin{array}{c}\text { Mean } \\
\text { Wind } \\
\text { Speed } \\
(\mathbf{K m} / \mathbf{h})\end{array}$} & \multirow[t]{2}{*}{$\begin{array}{c}\text { Rainfall } \\
\text { (mm) }\end{array}$} & \multicolumn{2}{|c|}{$\begin{array}{c}\text { Soil } \\
\text { Temperature } \\
\left({ }^{\circ} \mathrm{C}\right)\end{array}$} \\
\hline & Min. & Max. & Min. & Max. & & & $5 \mathrm{~cm}$ & $10 \mathrm{~cm}$ \\
\hline April & 20.2 & 33.6 & 44 & 67 & 5.6 & 8.9 & 25.7 & 36.8 \\
\hline May & 24.6 & 36.7 & 44 & 64 & 6.7 & 42.6 & 30.8 & 30.6 \\
\hline June & 30.5 & 39.9 & 42 & 62 & 7.8 & 1.4 & 36.2 & 36.0 \\
\hline July & 29.4 & 36.8 & 52 & 71 & 7.4 & 51.6 & 35.1 & 35.2 \\
\hline August & 28.4 & 35.7 & 62 & 81 & 6.7 & 16.5 & 34.3 & 34.8 \\
\hline September & 25.6 & 34.1 & 66 & 85 & 4.2 & 4.3 & 31.0 & 31.9 \\
\hline October & 20.5 & 31.5 & 63 & 83 & 2.7 & 17.7 & 26.6 & 27.0 \\
\hline November & 12.0 & 26.3 & 68 & 86 & 2.1 & 0.0 & 18.2 & 18.8 \\
\hline
\end{tabular}

\section{Fibre length (mm)}

Results revealed that heat stress effect adversely on fibre length especially during secondary wall development and fibre elongation leads to decreased fibre length and maturity, respectively. Genotypes tested under regulated and thermal stress varied from each other, and the length of the fiber in stress condition was also significantly reduced. The fibre length values were determined to be $27.8 \pm 0.15 \mathrm{~mm}, 27.3 \pm 0.14$ $\mathrm{mm}$ under normal and stress conditions respectively table 2 . At normal condition genotypes which were possessing high staple length genetically were AH (67)M, FH-142 and Cyto-178 with average staple length of 
28.9, 28.6 and $28.5 \mathrm{~mm}$ respectively, while minimum staple length was predicted by COKER 100/A-2 (26.4 mm) and ALLEPO-1 $(26.9 \mathrm{~mm})$. At heat stress condition maximum fibre length was showed by $\mathrm{AH}$ (67) M, Marvi and Cyto-178 with average staple length of 28.6, 28.3 and $28.2 \mathrm{~mm}$ respectively. Similarly, minimum fibre length was predicted by ACALA-63 (26.2 $\mathrm{mm})$ and COKER 100/A-2 (26.3 mm) table 3.

Table 2. Maximum, minimum \& mean values of fibre characteristics

\begin{tabular}{|c|c|c|c|c|c|}
\hline Traits & Condition & Maximum & Minimum & Means & S.E. \\
\hline \multirow{2}{*}{ Fibre Length (mm) } & Normal & 26.4 & 28.9 & 27.8 & \pm 0.15 \\
\cline { 2 - 6 } & Stress & 26.2 & 28.6 & 27.3 & \pm 0.14 \\
\hline \multirow{2}{*}{ Uniformity Index (\%) } & Normal & 79.8 & 86.3 & 83.4 & \pm 0.37 \\
\cline { 2 - 6 } & Stress & 78.6 & 85.8 & 81.8 & \pm 0.46 \\
\hline \multirow{2}{*}{ Fibre Strength (tppsi) } & Normal & 88.7 & 102.7 & 96.9 & \pm 0.75 \\
\cline { 2 - 6 } & Stress & 87.9 & 101.4 & 96.4 & \pm 0.76 \\
\hline \multirow{2}{*}{ Micronaire( g inch $\left.^{-\mathbf{1}}\right)$} & Normal & 3.8 & 6.0 & 5.0 & \pm 0.11 \\
\cline { 2 - 6 } & Stress & 3.5 & 5.8 & 4.8 & \pm 0.12 \\
\hline \multirow{2}{*}{ Ginning Out Turn (\%) } & Normal & 35.8 & 42.7 & 38.8 & \pm 0.48 \\
\cline { 2 - 6 } & Stress & 34.0 & 42.4 & 38.3 & \pm 0.49 \\
\hline
\end{tabular}

Table 3. Mean fibre characteristics of genotypes at normal \& stress conditions

\begin{tabular}{|c|c|c|c|c|c|c|c|c|c|c|}
\hline \multirow{2}{*}{ 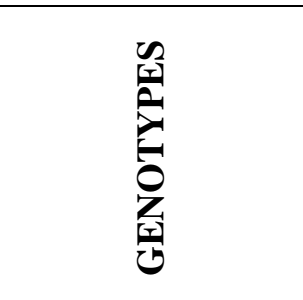 } & \multicolumn{2}{|c|}{$\begin{array}{c}\text { Fibre } \\
\text { Length } \\
(\mathrm{mm}) \\
\end{array}$} & \multicolumn{2}{|c|}{$\begin{array}{l}\text { Uniformity } \\
\text { Index (\%) }\end{array}$} & \multicolumn{2}{|c|}{$\begin{array}{c}\text { Fibre } \\
\text { Strength } \\
\text { (tppsi) } \\
\end{array}$} & \multicolumn{2}{|c|}{$\begin{array}{c}\text { Micronaire } \\
\text { Value } \\
(\mu g / i n c h)\end{array}$} & \multicolumn{2}{|c|}{$\begin{array}{c}\text { GinningOu } \\
\text { Turn (\%) }\end{array}$} \\
\hline & 苞 & 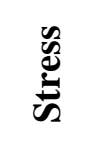 & Z & $\frac{\omega}{5}$ & 莺 & $\stackrel{\omega}{\omega}$ & 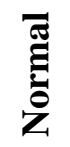 & $\stackrel{\tilde{\omega}}{\omega}$ & हี & $\underbrace{\infty}_{\infty}$ \\
\hline NIAB-111 & 27.7 & 27.1 & 83.1 & 81.3 & 93.0 & 91.9 & 4.8 & 4.6 & 42.1 & 42.4 \\
\hline ACALA-63 & 27.4 & 26.2 & 82.5 & 78.6 & 96.1 & 95.6 & 5.2 & 5.0 & 40.0 & 38.5 \\
\hline A-637-24 & 28.2 & 27.7 & 84.2 & 83.1 & 100.3 & 99.9 & 4.8 & 4.6 & 36.4 & 35.6 \\
\hline AL-4-42/22 & 27.6 & 26.8 & 83.0 & 80.4 & 95.3 & 95.0 & 5.3 & 5.2 & 36.4 & 34.0 \\
\hline A-7834 & 28.0 & 27.0 & 84.1 & 81.0 & 94.8 & 94.5 & 4.6 & 4.5 & 39.6 & 38.9 \\
\hline COKER 100/A-2 & 26.4 & 26.3 & 79.8 & 78.9 & 98.7 & 98.3 & 5.1 & 4.9 & 38.1 & 36.4 \\
\hline Albacala (69) 1 & 27.3 & 27.2 & 82.5 & 81.6 & 101.4 & 100.9 & 5.2 & 4.9 & 35.8 & 35.8 \\
\hline MNH-786 & 28.1 & 28.0 & 84.7 & 84.0 & 95.3 & 95.1 & 5.0 & 4.9 & 38.8 & 38.2 \\
\hline CIM-600 & 27.4 & 27.2 & 83.3 & 81.6 & 96.5 & 96.2 & 4.4 & 4.3 & 41.2 & 40.2 \\
\hline B-799 & 28.2 & 27.5 & 84.8 & 82.5 & 93.6 & 93.2 & 5.4 & 5.6 & 41.5 & 38.8 \\
\hline DAI-16 & 27.0 & 26.7 & 81.4 & 80.1 & 101.0 & 100.9 & 5.1 & 4.9 & 37.9 & 36.8 \\
\hline FH-142 & 28.6 & 28.1 & 85.4 & 84.3 & 98.5 & 98.1 & 5.3 & 5.2 & 42.0 & 41.4 \\
\hline CIM-534 & 28.0 & 27.3 & 83.9 & 81.9 & 94.4 & 93.5 & 4.7 & 4.6 & 42.7 & 41.3 \\
\hline AMSI-38 & 27.2 & 26.8 & 82.1 & 80.4 & 99.8 & 99.4 & 4.3 & 3.9 & 36.8 & 36.5 \\
\hline CASCOT BR-1 & 27.6 & 27.0 & 82.5 & 81.0 & 97.4 & 97.2 & 6.0 & 5.8 & 36.5 & 37.8 \\
\hline CYTO-178 & 28.5 & 28.2 & 84.9 & 84.6 & 102.7 & 101.4 & 4.8 & 4.7 & 37.8 & 38.1 \\
\hline AH(67)M & 28.9 & 28.6 & 86.3 & 85.8 & 95.2 & 94.9 & 3.8 & 3.5 & 38.4 & 39.7 \\
\hline Marvi & 28.5 & 28.3 & 85.4 & 84.9 & 99.2 & 98.8 & 5.2 & 5.0 & 37.3 & 36.6 \\
\hline D-3-75 & 27.4 & 27.1 & 82.4 & 81.3 & 88.7 & 87.9 & 5.4 & 5.3 & 39.4 & 40.8 \\
\hline ALLEPO-1 & 26.9 & 26.5 & 81.0 & 79.5 & 95.7 & 95.4 & 4.7 & 4.5 & 37.6 & 38.7 \\
\hline
\end{tabular}


Cotton fibre length reduced with high temperatures stress [14]. Night temperature between $15{ }^{\circ} \mathrm{C}$ and $21{ }^{\circ} \mathrm{C}$ is optimum for the development of maximum fibre length while reduction in length was observed when temperature deviate the required range. Fibre length affected in 3 to 25 days after anthesis due to changes in environmental conditions especially night temperature because cellulose deposition occurring on secondary wall in this period. As night temperature decreases from optimum, the elongation and length are also decreased [15]. The data of heat susceptibility index (HSI) revealed that among twenty (20) genotypes, five were heat tolerant from which two genotypes had higher fibre length, six genotypes were medium tolerant and nine showed maximum heat susceptibility index as heat sensitive. The genotypes in bottom most region VII are highly tolerant against heat stress with maximum fibre length fig 2 .

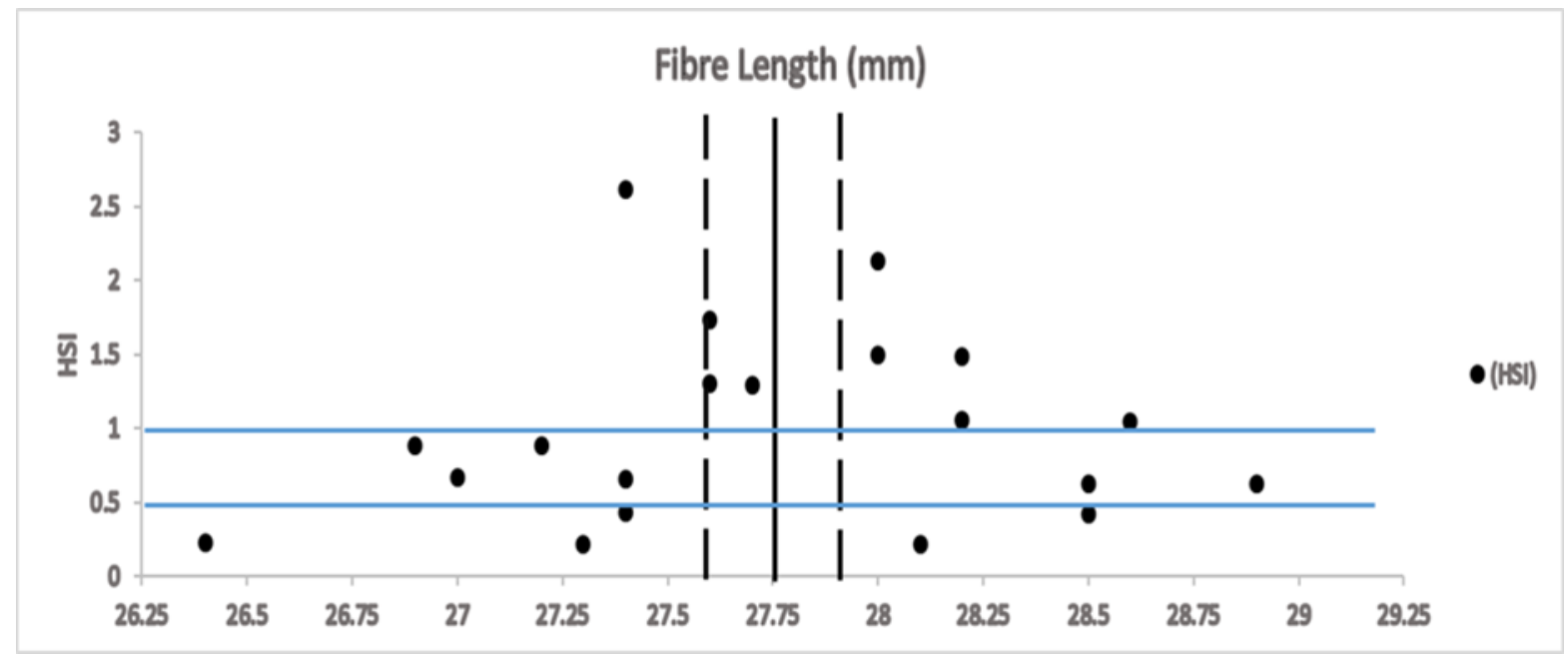

Figure 2. Fibre Length (mm) mean at normal conditions values and HSI

\section{Uniformity Index (\%)}

The results of uniformity index presented that under normal conditions of temperature, maximum uniformity was exhibited by AH(67)M, Marvi and FH-142 with mean uniformity index of $86.3,85.4 \& 85.4 \%$ respectively and minimum uniformity was showed by COKER 100/A-2 with average uniformity of $79.8 \%$. At heat stress condition, maximum uniformity was given by AH(67)M, Marvi\& Cyto-178 with average uniformity index of $85.8,84.9 \&$ $84.6 \%$ respectively while minimum uniformity was exhibited by ACALA-63 with uniformity of $78.6 \%$ table 3.Heat stress in cotton during boll development phase affect fibre quality especially fibre length and length uniformity [16, 17].The uniformity values were determined to be $83.4 \pm 0.37 \%$,
$81.8 \pm 0.46 \%$ under normal and stress conditions respectively table 2 .

The data of heat susceptibility index (HSI) revealed that among twenty (20) genotypes, five were heat tolerant from which two genotypes had higher uniformity index, six genotypes were medium tolerant and nine showed maximum heat susceptibility index and therefore found to beheat sensitive. The genotypes in bottom most region VII are highly tolerant against heat stress with maximum uniformity index fig 3 .

Fibre strength (tppsi)

Fiber quality tests showed that CYTO-178 exhibited maximum fibre quality under standard temperature conditions, Albacala (69) $1 \&$ A-637-24 with fibre strength of 102.7, 101.4 \& 101.3thousand pounds per square inch (tppsi) respectively and 
minimum fibre strength was showed by D-375 \&NIAB-111 with average fibre strength of $88.7 \& 93.00$ tppsi.At heat stress condition, maximum strength was given by CYTO-178, Albacala (69) 1 \& DAI-16 with fibre strength of 101.4, $100.9 \& 100.9$ tppsi respectively, while minimum strength was exhibited by same entry (NIAB-111) as strength reduced as stress was applied table 3. The fibre Strength values were determined to be 96.9 \pm 0.75 (tppsi), 96.4 \pm 0.76 (tppsi) under normal and stress conditions respectively table 2. Hesketh and Low stated that strength of fibre had positive association with high temperature. Snipes and Baskin [18] reported that heat unit accumulation during boll formation and development is a cause of high fibre strength in cotton. The data of heat susceptibility index (HSI) revealed that among twenty (20) genotypes, two were heat tolerant, twelve genotypes were medium tolerant and six showed maximum heat susceptibility index and found to be heat sensitive. The genotype in bottom most region VII is highly tolerant against heat stress with maximum fibre strength fig 4 .

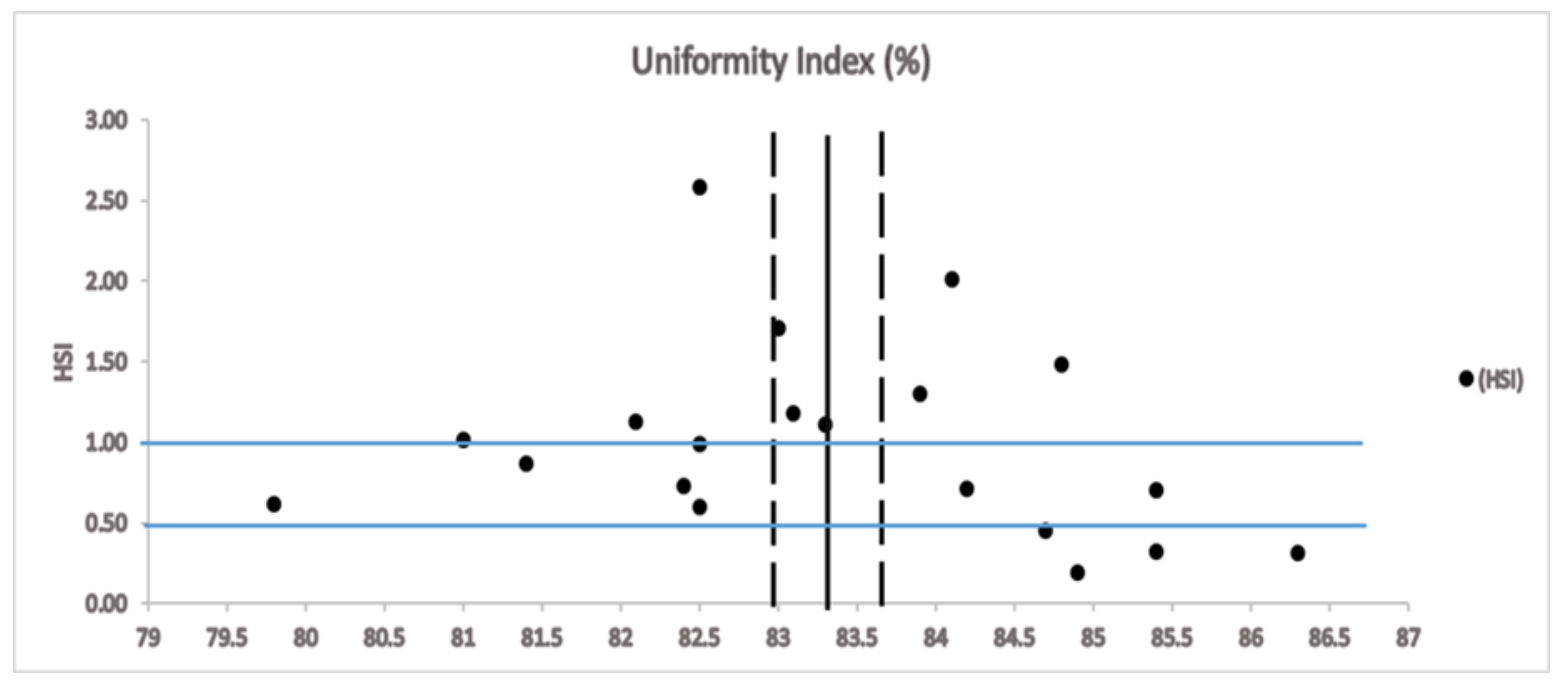

Figure 3. Uniformity Index (\%) mean at normal conditions values and HIS

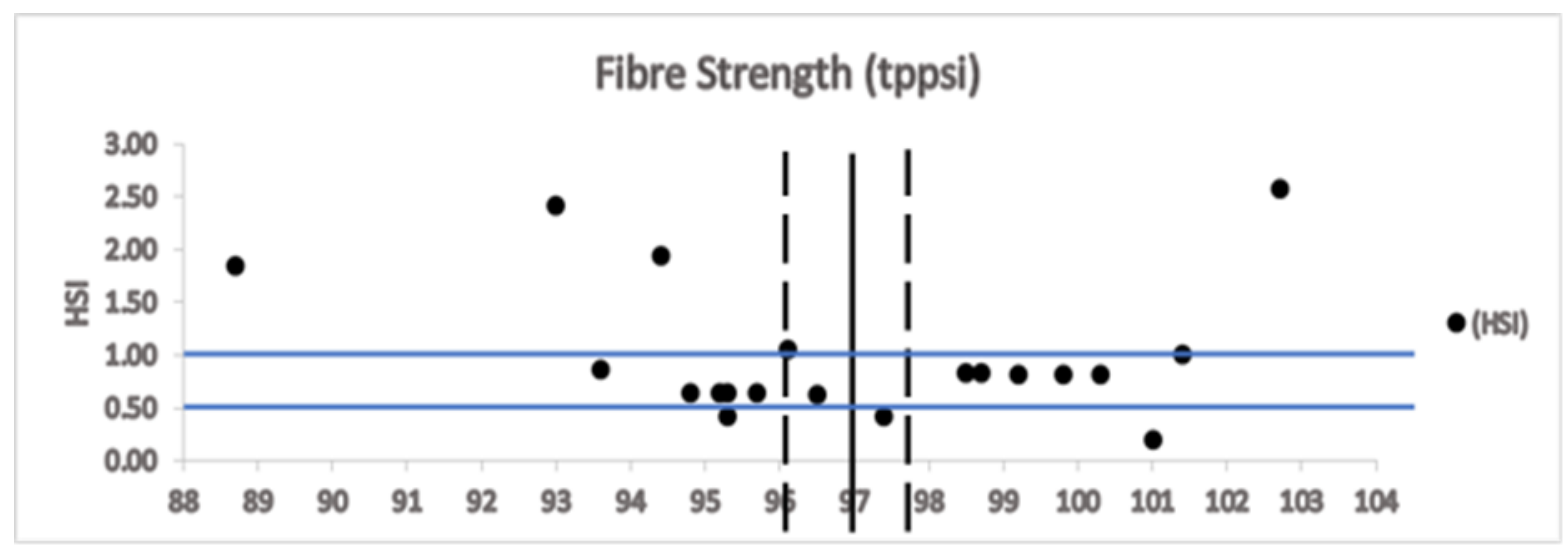

Figure 4. Fibre strength (tppsi) mean at normal conditions values and HSI 
Micronaire value $\left(\mu \mathrm{g}\right.$ inch $\left.^{-1}\right)$

At normal temperature condition, maximum micronaire value was predicted by genotypes CASCOT BR-1, B-799 \& FH-142 with mean micronaire values of $6.0,5.4 \& 5.3 \mu \mathrm{g} \mathrm{inch}^{-1}$, while minimum micronaire value was presented by AH-67-M (3.8 $\left.\mu \mathrm{g} \mathrm{inch}^{-1}\right)$ and AMSI-38 (4.3 $\mu \mathrm{g}$ inch $\left.^{-1}\right)$.As stress was imposed the maximum micronaire value was exhibited by CASCOT BR-1, B-799 \& D-375 with average micronaire values of 5.8, 5.6 \& $5.3 \mu \mathrm{g} \mathrm{inch}^{-1}$ respectively while minimum value was given by AH-67-M \& AMSI-38 with average value of $3.5 \& 3.9 \mu \mathrm{g}$ inch $^{-1}$ respectively table 3 . The micronaire values were determined to be $5.0 \pm 0.11\left(\mu \mathrm{g} \mathrm{inch}^{-1}\right)$, $4.8 \pm 0.12\left(\mu \mathrm{g} \mathrm{inch}^{-1}\right)$ under normal and stress conditions respectively table 2. Two researchers [19, 20] observed high micronaire value (coarse fibre) due to accumulation of heat units during fibre development under severe heat stress. The micronaire value has a positive correlation with heat stress. So, under heat stress conditions increase in fibre thickness observed which mainly affected due to the radiation [21].

The data of heat susceptibility index (HSI) revealed that among twenty (20) genotypes, eighteen were heat tolerant from which nine had less than 5.0 micronaire value and two genotypes were medium tolerant with high micronaire. The genotype in bottom most region I was highly tolerant against heat stress with less micronaire value fig 5 .

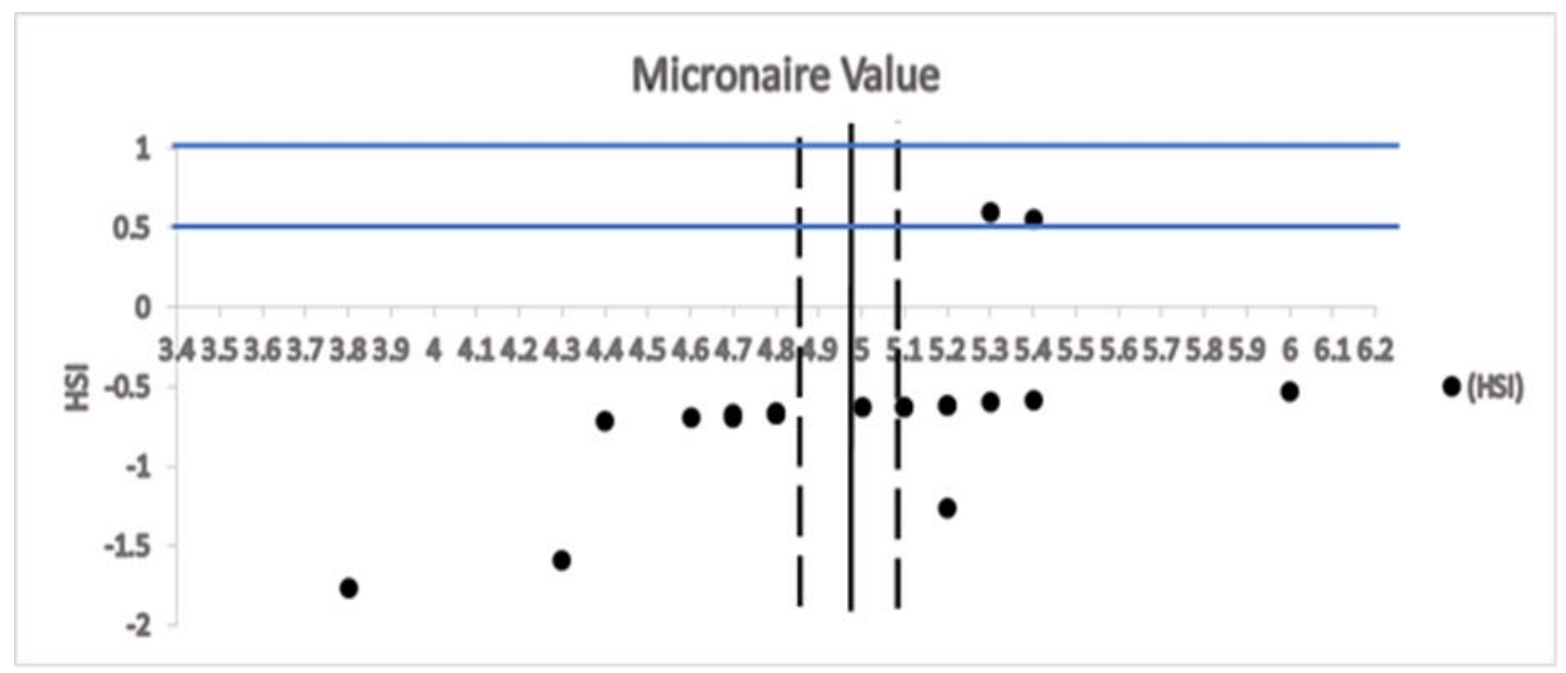

Figure 5. Micronaire value $\left(\mu \mathrm{g}\right.$ inch $\left.^{-1}\right)$ mean at normal conditions values and HSI

\section{Ginning out turn (\%)}

Maximum ginning out turn was observed in normal condition by CIM-534, NIAB-111 $\& \mathrm{FH}-142$ with average values of $42.7,42.1$ \& $42.0 \%$ respectively, while lowest ginning out turn was exhibited by Albacala (69) 1, A637-24 \& AL-4-42/22 with mean ginning out turn of $35.8,36.4 \& 36.4 \%$ respectively. Highest ginning out turn was recorded at heat stress scenario byNIAB-111, FH-142 \&CIM534 with average ginning out turn of 42.4 ,
$41.4 \& 41.3 \%$ respectively stating that GOT has exploded when stress was incorporated. Likewise, the lowest ginning-out turn was predicted by AL-4-42/22 \& and A-637-24 with ginning out turn of $34 \& 35.6 \%$ respectively table 3 . The ginning out turn values were determined to be $38.8 \pm 0.48(\%)$, $38.3 \pm 0.49(\%)$ under normal and stress conditions respectively, hesketh and Low (1968) reported adverse effect of heat stress on the ginning out turn. Major component of 
fibre was carbohydrate and under stress condition, reduction in availability of required carbohydrate could be manifested in low ginning out turn [22]. The data of heat susceptibility index (HSI) revealed that among twenty (20) genotypes, seven were heat tolerant from which two have higher ginning out turn value, only one has medium tolerant to heat and twelve genotypes were highly susceptible to heat index. The genotypes in bottom most region VII was highly tolerant against heat stress with highginning out turn fig 6 .

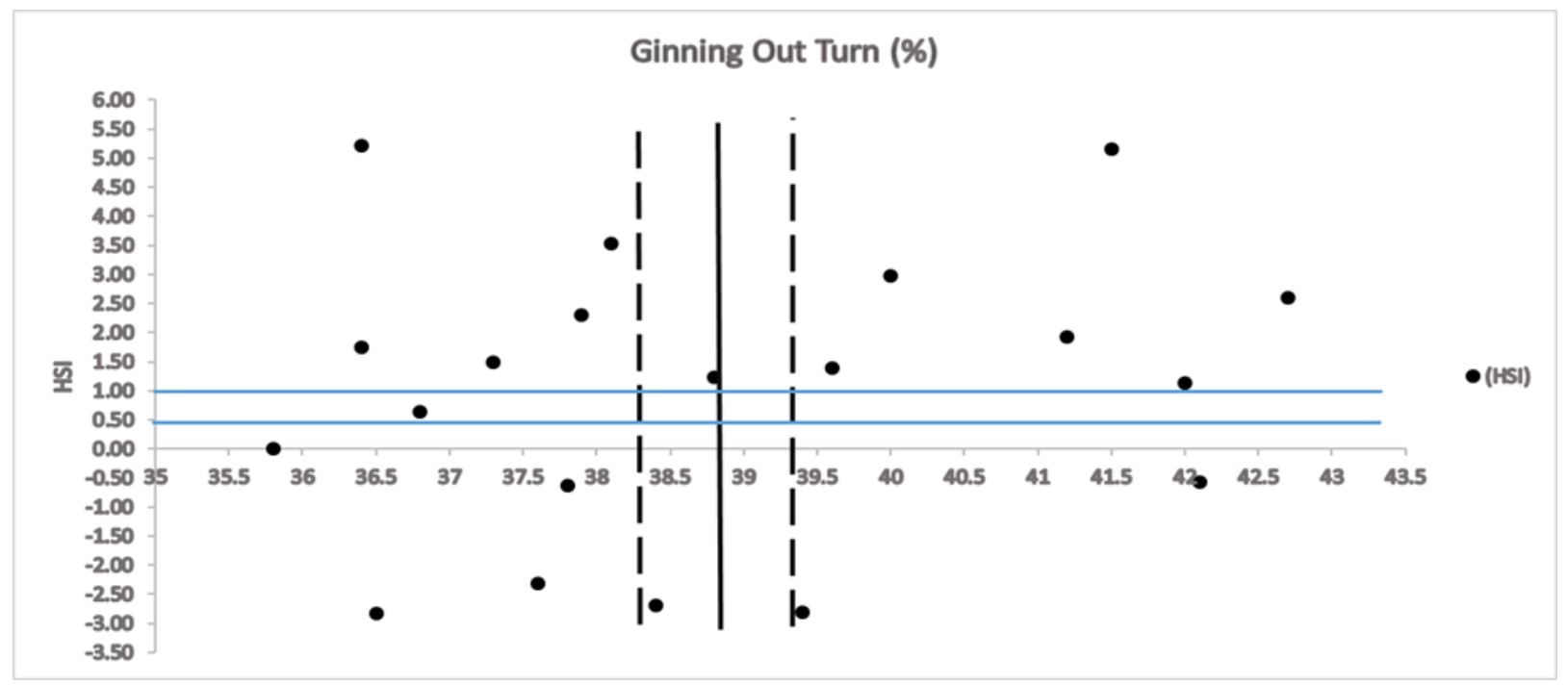

Figure 6. Ginning out turn (\%) mean at normal conditions values and HSI

\section{Conclusion}

Under heat stress conditions significant deterioration of fibre traits occurred but the level of decrease in quality varies among the genotypes. The use of trait specific heat tolerant genotypes is significant in breeding program to develop new varieties with good quality fibre traits. Sowing time also plays important role to escape the cotton crop from severe heat stress environment. March or early April sowing should be avoided and new cotton regions should be search out for production of better fibre quality cotton to provide textile industry to reduce the good quality cotton import. The screening of entire available germplasm is also very essential so that we can get maximum genotypes showing heat tolerance for different economical traits. Authors' contributions

Conceived and designed the experiments: $\mathrm{K}$ Hussain \& A Hussain. Preformed the experiments: D Iqbal, MI Sarwar \& A Qayyum. Analyzed the data: MI Gill \& NA Wahocho. Contributed reagents/ materials/ analysis tools: NA Wahocho, D Iqbal \& A Qayyum. Wrote the paper. D Iqbal \& K Hussain.

\section{References}

1. FAO (2005). Production yearbook in agriculture. FAO, Rome, Italy.

2. Baker DN (1965). Effects of certain environmental factors on net assimilation in cotton. Crop Sci 5: 53-5.

3. Singh RP, Vara Prasad PV, Sunita K, Giri SN, \& Reddy KR (2007). Influence of high temperature and breeding for heat tolerance in cotton. Adv in Agron 93: 313386.

4. Roberts EM, Rao NR, Huang JY, Trolinder NL, \& Haigler CH (1992). Effects of cycling temperatures on fiber metabolism in cultured cotton ovules. Plant Physiol 100: 979-86. 
5. Park Y-H, Alabady MS, Ulloa M, Sickler B, Wilkins TA, Yu J, Stelly DM, Kohel RJ, Shihy OMI, \& Cantrell RG (2005). Genetic mapping of new cotton fiber loci using EST-derived microsatellites in an interspecific recombinant inbred line cotton population. Mol Gen \& Genom 274: 428-441.

6. Khan AI, Khan IA, \& Sadaqat HA (2008). Heat tolerance is variable in cotton (Gossypium hirsutum L.) and can be exploited for breeding of better yielding cultivars under high temperature regimes. Pak J of Bot 40:2053-2058.

7. Rahman H (2006). Number and weight of cotton lint fibres: variation due to high temperatures in the field. Aus J of Agri Res 57:583-90.

8. Noshair K, Faqir MA, Khan AA, \& Rashid A (2014). Measurement of canopy temperature for heat tolerance in upland cotton: variability and its genetic basis. Pak J of Agri Sci 51(2):359-365.

9. Farooq J, Khalid M, Muhammad WA, Atiq RM, Imran J, Valentin PMI, \& Nawaz N (2015). High temperature stress in cotton (Gossypium hirsutum L.). Extreme Life, Biospeology and AstrobiolBioflux 7:34-44.

10. ASTM Committee (2008). Standard test methods for measurement of physical properties of cotton fibers by high volume instruments. ASTM Designation: D 586705. Amer. Soc. for Test. \& Mater., Philadelphia, USA.

11. Fischer RA, \& Maurer R (1978). Drought resistance in spring wheat cultivars. I. Grain yield responses. Aus J of Agri Res: 897-912.

12. Khanna-Chopra $\mathrm{R}$, \& Viswanathan $\mathrm{C}$ (1999). Evaluation of heat stress tolerance in irrigated environment of $\mathrm{T}$. aestivum and related species. I. Stability in yield and yield components. Euphytica, 106(2): 169180.

13. Steel RGD, Torrie JH, \& Dickey DA (1996). Principles and procedures of statistics: A biometrical approach. Mcgraw-Hill, New York.

14. Stockton JR, Doneen LD, \& Walhood VT (1961). Boll shedding and growth of the cotton plant in relation to irrigation frequency. Agron J 53: 272-275.

15. Gipson JR, \& Joham HE (1968). Influence of night temperature on growth and development of cotton (Gossypium hirsutum L.). Agron J 60: 292-295.

16. Hesketh JD, \& Low A (1968). Effects of temperature on components of yield and fiber quality of cotton varieties of diverse origin. Cotton Grow Rev 45:243-247.

17. Ramey HH (1986). Stress influences on fiber development. In: Mauney J R and Stewart McD. (Eds). Cotton Physiology. The Cotton Foundation, Memphis pp: 351.

18. Snipes CE, \& Baskin CC (1994). Influence of early defoliation on cotton yield, seed quality, and fiber properties. Field Crops Res. 37:137-143.

19. Johnson RM, Bradow JM, \& SassenrathCole GF (1997). Modeling of cotton fiber quality from environmental parameters. Proceedings 1997 Beltwide Cotton Conference pp. 1454-1455.

20. Bradow JM, Bauer PJ, Hinojosa O, \& Sassenrath-Cole GF (1997). Quantitation of cotton fibre-quality variations arising from boll and plant growth environments. The Euro J of Agron 6:191-204.

21. Pettigrew WT (1995). Source-to sink Manipulation effects on cotton fiber quality. Agron J 87: 947-952.

22. Oosterhuis DM (1999). Yield response to environmental extremes in cotton. Natl Cot Coun Amer 193: 30-38. 